\title{
The Incidence of Tuberculosis and Various Factors Associated With Tuberculosis in Seropositive Patients
}

\author{
Rakesh Kumar, Sweta Muni*, Somya Sinha, Shailesh Kumar and S.K.Shahi
}

IGIMS, Patna, India

*Corresponding author

\section{A B S T R A C T}

Tuberculosis (TB) is the commonest opportunistic infection and cause of death in patients with Human Immunodeficiency Virus (HIV) in developing countries. World Health Organization (WHO) recommends 85\% treatment success rate for

Keywords

Tuberculosis (TB),

Treatment, HIV patients

Article Info

Accepted:

12 June 2019

Available Online:

10 July 2019 all TB cases as an indicator of TB control. The study aimed at determining TB co infection among the seropositive cases. It was a cross-sectional study among seropositive patients whose sociodemographic characteristics with treatment history were obtained using a semi-structured questionnaire. Sputum samples were collected and tested for acid-fast bacilli (AFB) using a standard method according to national guideline for $\mathrm{TB}$ treatment to determine treatment success rate. Treatment success was defined as any HIV positive patient with a diagnosis of TB by acid-fast bacilli (AFB) smear positivity at diagnosis, who after 6 months of complete treatment becomes smear negative. A total of 209 HIV patients were enrolled for this study. Fifty-nine (54.1\%) were females, 106 (97.3\%) were newly treated for TB. Eighty-five (78.0\%) were treated in a government health facility. A total of 29 had tested positive for tuberculosis using Gene xpert and $\mathrm{ZN}$ microscopy. In our study we found 29 cases of tuberculosis among 209 seropositive patients which is $13.8 \%$.

\section{Introduction}

Tuberculosis (TB) is an airborne infectious disease caused by Mycobacterium tuberculosis and primarily affects the lungs (pulmonary) but can also affect other parts of the body (extra-pulmonary) (1). TB is curable if patients with drug-susceptible organisms are treated on time and are given sufficient uninterrupted therapy (2). Despite the fact that $\mathrm{TB}$ is treatable and curable, it has proven difficult to eliminate, and this has been worsened by the HIV-AIDS pandemic (3). TB is one of the most common infections that threaten people living with HIV (PLWH) in developing world because they are 26-31 times more likely to develop TB than persons without HIV (2). Integrating TB and HIV services to ensure $90 \%$ of $\mathrm{TB}$ patients are tested for HIV and HIV patients are screened for $\mathrm{TB}(8)$ can reduce at least 10000 deaths each year.(9) Priority steps to control TB have 
been outlined and include increasing cure rates to $85 \%$, improving case detection rates to $70 \%$, integrating TB with HIV, and identifying and treating drug resistant TB(9). However, there is need to ensure that knowledge and attitudes at the population level are understood and if low, then improved to optimal levels for sustainable TB control.

\section{Materials and Methods}

This was a cross sectional study conducted in IGIMS, Patna, from May to April, 2016. 109 Subjects were recruited from the patients attending the HIV care and treatment clinic. Eligible subjects were those aged 10 years and above and who agreed to participate in the study irrespective of their previous tuberculosis status. Patients on tuberculosis treatment were excluded from the study. A complete biodata of each patient was obtained with the aid of a form designed to include age, sex, occupation, marital status, address, and religion. Other information sought and obtained were date and time of specimen collection. Spot samples were collected under the TB laboratory supervisor and patients were instructed on how to collect the early morning (collection) samples. Each sample was examined to ensure that it was sputum and not saliva.

The sputum samples were handled in a class I safety cabinet. Sputa accepted were purulent, opaque or greenish in appearance. Samples that were heavily blood stained (clots) were treated with Sodium hypochloride to lyse the clots and concentrated by centrifugation subsequently freeing the bacteria ready for staining. Smears were prepared, fixed and stained by Ziehl-Neelsen staining methods for acid fast bacilli (AFB). The smears were examined for acid fast bacilli under oil immersion (x 100) objective. Then the samples were subjected to Gene Xpert the same day or the following day.

\section{Results and Discussion}

Among 209 confirmed seropositive HIV/AIDS patients examined, 29 were positive for Acid Fast Bacilli (AFB) showing a prevalence rate of $13.8 \%$ tuberculosis in HIV/AIDS patients (Table 1). It was observed from Table 1 that, out of the 29(13.8\%) HIV/TB co-infection patients, 12 (41.30\%) were in the age group of 30-40 years, followed by $7(24.38 \%)$ in the age group of greater than 50 years, and only $3(10.30 \%)$ in the age group of less than 20 years. The mean age of the patients was $38.1 \pm 3.2$ years. There were $17(58.58 \%)$ males and $12(42.42 \%)$ females. As per the modified BG Prasad classification, most of the patients $20(68.28 \%)$ belonged to lower class followed by $7(24.79 \%)$ middleclass; while only $2(6.23 \%)$ from upper class. With more than half $(72.95 \%)$ of the study population were married, while $(17.40 \%)$ either divorced/widow or separated from their family. Education level of the study population indicated that $6(20.74 \%)$ were illiterates and $11(37.58 \%), 5(17.79 \%)$, and $6(20.81 \%)$ had education levels of primary, secondary, graduation, respectively.

Occupation of the study population of HIV/TB co-infection showed that $(37.9 \%)$ were laborers, followed by $(24.65 \%)$ was farmers and $(27.11 \%)$ were driver. Similarly a study done by Padyana et al., (12) at a tertiary care hospital of South India, among 200 HIV positive patients, showed that 54 (27\%) patients had HIV/TB co-infection and remaining 146 (73\%) were HIV positive alone. In developing countries, TB is one of the most common life-threatening infections among the persons living with HIV/AIDS. An estimate shows that around 5.1 million people are infected with HIV and about half of these cases are co-infected with tuberculosis. (14) In India, approximately 200000 of these HIV infected persons develop active TB each year. (15) Incidence of HIV/TB co-infection was 
reported to be very high $(50 \%)$ in sub-Saharan Africa compared to that in Asia. (16) The rates of HIV/TB co-infection have been reported to vary in different regions of India. It was found to be between $0.4 \%$ and $20.1 \%$ in north India. (17) However, the incidence was $3.2 \%$ in
1991, which increased to $20.1 \%$ in 1996 in south India. (18) This prevalence of HIV/TB co-infection is different from the national figure $(60.30 \%)$, (19) but almost similar $(27.3 \%)$ to that of another study done by Dev et al., (20).

\begin{tabular}{|l|c|c|}
\hline \multicolumn{2}{|c|}{ Table.1 } \\
\hline Age(yrs) & Number & Percentage \\
\hline$<\mathbf{2 0}$ & 3 & 10 \\
\hline $\mathbf{2 0 - 3 0}$ & 4 & 13 \\
\hline $\mathbf{3 0 - 4 0}$ & 12 & 41 \\
\hline $\mathbf{4 0 - 5 0}$ & 3 & 10 \\
\hline$>\mathbf{5 0}$ & 7 & 24 \\
\hline Sex & & 58.6 \\
\hline Male & 17 & 42.4 \\
\hline Female & 12 & 6.9 \\
\hline Socioeconomic status & & 24.1 \\
\hline Upper & 2 & 68.9 \\
\hline Middle & 7 & \\
\hline Lower & 20 & 72.4 \\
\hline Marital status & & 17 \\
\hline Married & 21 & 10.3 \\
\hline Divorced/widow/separated & 5 & 20.6 \\
\hline Single & 3 & 37.9 \\
\hline Education & & 17.2 \\
\hline Illetrate & 6 & 10.3 \\
\hline Primary & 11 & 20.6 \\
\hline Middle school & 5 & \\
\hline Secondary & 3 & 27.5 \\
\hline Graduate & 6 & \\
\hline Occupation & & \\
\hline Housewife/unemployed & & \\
\hline Farmer & & \\
\hline Driver & & \\
\hline Labourer & & \\
\hline & & \\
\hline
\end{tabular}


Since the increase in HIV infection rate leads to increase in tuberculosis disease, there is need to reexamine the strategies for their effective control. The development of programs with an integrated approach to inducing behavioral change and promoting use of condoms may reduce the infectivity of HIV transmitters and the susceptibility of HIV-exposed persons. The most important aspect of this control program is public awareness and good health education on how tuberculosis and HIV are transmitted.

\section{References}

1. Kingsley ChinedumOchei by. A review of community tuberculosis care intervention in Nigeria - A care study of NGO intervention - A Capstone Project - A Case Study. South Am J Public Heal. 2014; (21): 2309-6470.

2. Nik NorRonaidi NM, Mohd NS, Wan Mohammad Z, Sharina D, Nik Rosmawati NH. Factors associated with unsuccessful treatment outcome of pulmonary tuberculosis in Kota Bharu, Kelantan. Malaisaian Journal of Public health. 2011; 11(1): 5

3. WHO. Tuberculosis and HIV. 2012. Accessed $2015 \mathrm{Jul} 27$

4. Churchyard GJ, Mametja LD, Mvusi L, Ndjek N, Hesseling AC, Reid A BS. Tuberculosis control in South Africa: Successes, challenges and recommendations. South African Med J 2014; 104:244-8. https://doi.org/10.7196/SAMJ.7689

5. Karim SSA, Churchyard GJ, Karim QA, Lawn SD. HIV infection and tuberculosis in South Africa: an urgent need to escalate the public health response. Lancet 2009; 374:921-33. https://doi.org/10.1016/ S0140-6736(09)60916-8 PMID: 19709731

6. Nwabuko CO, Ejele OA, Chuku A, Nnoli MA, Chukwuonye II (2012). Prevalence of Tuberculosis-HIV Coinfection and Relationship between Tuberculosis and CD4/ESR in HIV Patients in Niger Delta Region of Nigeria. J. Dent. Med. Sci., 2(4): 1-11.

7. Olaniran $\mathrm{O}, \mathrm{R}$ E Hassan-Olajokun, MA Oyovwevotu RA Agunlejika (2011). Prevalence of Tuberculosis among HIV/AIDS Patients in Obafemi Awolowo University Teaching Hospital.

8. Auld AF, Ekra KA, Shiraishi RW, Tuho MZ, Kouakou JS, Mohamed F, et al., Temporal trends in treatment outcomes for HIV-1 and HIV-2-infected adults enrolled in Co^te d'Ivoire's national antiretroviral therapy program. PLoS One 2014; 9: e98183.

9. Akanbi MO, Achenbach CJ, Feinglass J, Taiwo B, Onu A, Pho MT, et al., Tuberculosis after one year of combination antiretroviral therapy in Nigeria: A retrospective cohort study. AIDS Res Hum Retroviruses 2013; 29: 931-7.

10. Mor Z, Lidji M, Cedar N, Grotto I, Chemtob D. Tuberculosis incidence in HIV/AIDS patients in Israel, 1983-2010. PLoS One 2013; 8: e79691.15.

11. Moore D, Liechty C, Ekwaru P, Were W, Mwima G, Solberg P, et al., Prevalence, incidence and mortality associated with tuberculosis in HIV-infected patients initiating antiretroviral therapy in rural Uganda. AIDS 2007; 21: 713-9.

12. Van Rie A, Westreich D, Sanne I. Tuberculosis in patients receiving antiretroviral treatment: Incidence, risk factors, and prevention strategies. J Acquir Immune DeficSyndr 2011; 56: 349-5514

13. Salami AK, Katibi IA. Human immunodeficiency virus associated tuberculosis: Pattern and trend in the University of Ilorin Teaching Hospital. Afr J Med MedSci 2006; 35: 457-60. 
14. Iliyasu Z, Babashani M. Prevalence and predictors of tuberculosis coinfection among HIV-seropositive patients attending the Aminu Kano Teaching Hospital, Northern Nigeria. J Epidemiol 2009; 19: 81-7.

15. Charurat M, Oyegunle M, Benjamin R, Habib A, Eze E, Ele P, et al., Patient retention and adherence to antiretrovirals in a large antiretroviral therapy program in Nigeria: A longitudinal analysis for risk factors. PLoS One 2010; 5: e1058419.
16. Govt. of India, Ministry of Health and Family. Welfare, National AIDS Control Organisation. National guidelines for clinical management of HIV/AIDS. 2003. http://www.nacoindia.org

17. Dey SK, Pal NK, Chakrabarty MS. Cases of immunodeficiency virus infection and Tuberculosis: Early experience of different aspects. J Indian Med Assoc. 2003; 101: 291-2.

\section{How to cite this article:}

Rakesh Kumar, Sweta Muni, Somya Sinha, Shailesh Kumar and Shahi, S.K. 2019. The Incidence of Tuberculosis and Various Factors Associated With Tuberculosis in Seropositive Patients. Int.J.Curr.Microbiol.App.Sci. 8(07): 1690-1694.

doi: https://doi.org/10.20546/ijcmas.2019.807.200 